Article

\title{
Refugee Mobilities and Institutional Changes: Local Housing Policies and Segregation Processes in Greek Cities
}

\author{
Pinelopi Vergou ${ }^{1, *}$, Paschalis A. Arvanitidis ${ }^{1}$ and Panos Manetos ${ }^{2}$ \\ ${ }^{1}$ Department of Economics, University of Thessaly, 38333 Volos, Greece; E-Mails: pvergou@uth.gr (P.V), \\ parvanit@uth.gr (P.A.) \\ 2 Department of Planning and Regional Development, University of Thessaly, 38333 Volos, Greece; \\ E-Mail: pmanetos@uth.gr \\ * Corresponding author
}

Submitted: 16 December 2020 | Accepted: 16 March 2021 | Published: 27 April 2021

\begin{abstract}
Many studies have explored the dynamics of immigrant and refugee settlement at the local level, highlighting that it is actually a two-way process: On the one hand, the local socio-political context specifies the conditions for refugee inclusion, and on the other, migrant mobility leads to the transformation of localities in various ways. In Greek cities, the social practices of local actors have played an important role in the implementation of the immigration policy, where refugees were perceived as a threat to personal and community security. Yet, new forms of social mobilisation and solidarity by individual citizens and community initiatives have worked to alter these attitudes, mitigating tensions and obstacles in refugee acceptance. The article draws on the Greek experience to explore the role and importance of the local socio-political texture in refugee inclusion, shedding light on how it gave rise to various local initiatives that inform refugee allocation as well as urban transformation and institutional change. In methodological terms, the article considers three neighbouring Greek cities as case studies to identify the different institutional and policy responses to refugee accommodation, giving rise to different paths and forms of social inclusion. The study reveals the complexity and context of the social-spatial diversity that refugees face but also the transformation dynamics of local states and civil society.
\end{abstract}

\section{Keywords}

local welfare state; municipalities; refugee accommodation; segregation; social initiatives; solidarity

Issue

This article is part of the issue "Migration-Led Institutional Change in Urban Development and Planning" edited by Robert Barbarino (TU Dortmund University, Germany), Charlotte Räuchle (Free University Berlin, Germany) and Wolfgang Scholz (TU Dortmund University, Germany).

(C) 2021 by the authors; licensee Cogitatio (Lisbon, Portugal). This article is licensed under a Creative Commons Attribution 4.0 International License (CC BY).

\section{Introduction}

Over the last years, and particularly after 2012, Greece has received a substantial number of immigrants, coming primarily from Syria, Afghanistan, and Iraq as a consequence of the general political instability and wars in the area. As a result, more than one million refugees have entered the country having as final destinations other countries in Northern and Western Europe. Yet, the closure of the so-called Western Balkans route and the European Union (EU)-Turkey Agreement on refugee and migrants in the Spring of 2016 have confined uncontrolled and irregular movements both towards and within the EU (European Council, 2016), leaving around 76,000 refugees and asylum seekers trapped in Greece for an indefinite period (United Nations High Commissioner for Refugees [UNHCR], 2019).

Although the situation has preoccupied both Greek society and the state authorities, giving rise to many debates, such concerns did not materialise in an integrated and solid planning policy regarding refugee and asylum seekers' accommodation on the part of the state. 
Instead, in an attempt to deal with such a pressing and controversial issue, the country deployed several strategies and measures treating the matter of spatial allocation, settlement and integration of the incomers on a rather ad hoc and diversified basis. Thus, this multi-level approach to the so-called refugee crisis has resulted in different housing outcomes and approaches to integration in many cities, corresponding to different levels of engagement and cooperation that the local social actors (civil society, NGOs, religious organisations, etc.) have exhibited. In some cases, innovative ways of social inclusion and acts of solidarity were made prevalent, whereas, in others, instances of social exclusion and marginality have been documented (Arvanitidis, Vergou, Manetos, \& Grigoriou, 2020; Vergou, 2019). Overall, the different needs of the refugees were treated in varied ways based on the local context and social dynamics, sometimes in coordination and others in disengagement with the state and national directives (which mainly follow the EU policies and the framework set by the Common European Asylum System). Certainly, the issue of refugee integration has been at the forefront of the academic discussion, giving rise to an extended and growing literature. Notably, the current journal alone has published several articles and thematic issues on the matter, exploring the socio-spatial aspects of the phenomenon (e.g., Urban Planning's thematic issues on "European Cities Planning for Asylum," "Urban Arrival Spaces: Social Co-Existence in Times of Changing Mobilities and Local Diversity," and "Cities of Inclusion-Spaces of Justice"), and especially how various 'arrival infrastructures' provide resources to newcomers in diverse local environments.

Yet, refugee integration remains a rather contested term and a controversial discussion, especially concerning the urban contexts. Integration characterizes different forms and access to functional, social, and symbolic resources conceptualised as culture, support and care networks, and social bonds. Furthermore, concerning different levels of governance, local state and large cities formulate their own perspectives to migrant integration which does not always coincide with that of the national level (Scholten \& Penninx, 2016). Although integration has traditionally been correlated with national identity and community (Penninx \& Garcés-Mascareñas, 2016), cities become more autonomous, formulating their own perspectives and policies in finding solutions for housing, education, and health provision, as well as social aspects of community connectivity.

In our contribution, we analyse the interdependencies between local policies and segregation processes and we try to shed light on spatial integration processes and the barriers and challenges that refugees face in urban contexts. With all these under consideration, the article seeks to explore how the local, social, and material resources (such as support and care networks, community initiatives, social centres) and institutional and organisational resources (municipalities, NGOs, religious organisations), have evolved in specific initia- tives in refugee accommodation and how they impact refugee allocation dynamics and institutional change in Greece. Furthermore, we analyse how different local policy responses have given rise to different segregation patterns revealing the weaknesses and challenges of refugee inclusion as this is experienced in selected, yet typical, Greek cities.

The analysis of path-dependencies of national and local housing systems is crucial to understanding the processes of residential settlement of immigrants. Thus, we highlight the specificities and peculiarities of Southern Europe and Greece in particular regarding urban development and housing provision in general. We stress that crucial to understanding institutional transformations and their effects on the spatial integration of refugees is the role of the Greek welfare system, with its interplay of familial and clientelistic political practices and its traditional weakness to provide affordable housing (Maloutas, Siatista, \& Balambanidis, 2020).

As becomes evident, analysis takes into account the urban context and dynamics of the migrationled transformation processes, the local (political and social) environment, the conditions of the recent crisisinflicted Greek welfare regime, and the complexity of interactions between different territorial jurisdictions (Arbaci, 2019; Mingione \& Oberti, 2003). Following Andreotti, Mingione, and Polizzi (2012), our approach acknowledges that in local welfare regimes, different arrangements of formal and informal actors, special configurations of population needs, social policy providers and resources are emerging and intersect with other systems and territorial levels. In this context, the socioterritorial approach to urban inequalities is more appropriate to understand different levels of interactions and complex social relations from global to local (Oberti \& Preteceille, 2018).

\section{Spatial Integration Processes at the Local Scale: The Dual Housing Model and Path-Dependencies}

Drawing on a comparative study of local experiences with refugee accommodation in three small and medium-sized cities in Greece, we provide a closer understanding of each city, with the local spatial integration strategies, community resources and particular characteristics of their civil societies. Our contribution, through the comparative analysis of local cases, is to highlight the various complexities of the housing processes in the localities where refugees are settled and to provide a better understanding of the interdependencies between local policies and segregation processes. These may involve varying arrangements and cooperation between public institutions, intermediate organisations, the Church, family networks, and the local community. Concerning this, we examine different forms of civil society engagement and how and to what extent they contribute to the social inclusion of the newcomers and the transformation of local urban policies. In this context, 
and in response to a variety of contextual dependent factors and conditions, the transition to multilevel governance and the municipality's active or passive stance on welfare integration policies are far from a linear and uniform process. Specific local and cultural contexts give rise to diversified mixes of actors and strategies for implementing social policies.

The recent national legislation (Greek Government, 2020a, 2020b) signals a change of focus with emphasis on the local state and a step forward for the changing of generic 'emergency processes' to more locallyoriented policies. In this regard, implemented housing policies and integration programs seem to exhibit rather top-down (centralist) logic, and yet, at the same time, there is multi-level governance as local players are heavily involved in the process, shaping the path of institutional change. Thus, a network of 13 cities has been established where municipalities have a major role in the implementation of the housing policy of the newcomers and recently on the provision of an integration program to promote integration processes (Hellenic Integration Support for Beneficiaries of International Protection [HELIOS], 2019). Also, the relocation of refugees in open facilities camps near the cities have activated the municipalities to cooperate with international actors, NGOs, and humanitarian organisations. Different social initiatives and municipal entrepreneurship companies-such as e-trikala, a municipal development agency of the city of Trikala, which maintains the operation of 70 apartments with 500 refugees accommodated and ANKA, a municipal development agency of the city of Karditsa, which implemented the accommodation and assistance to asylum seekers in the city and created the intercultural centre 'Stavrodromi'(Crossroad) - took an active role in the social inclusion of the newcomers in local communities, differently from what was envisaged by the central immigration policy of the state.

In this framework, it is important to outline the contextual background and path-dependencies of national and local housing systems within which our case-study cities operate. The Greek welfare system exhibits the strong familistic and clientelistic structure that is apparent to the welfare regimes of the other Mediterranean countries. Overall, the family plays a prominent role as the main provider of welfare and as a key agent in social-economic and political reproduction (Bureau of European Policy Advisers, 2011; Oosterlynck et al., 2013a). Strong family ties not only work to assure financial support to their members, but family extended links and networks enhance such dynamics, taking advantage of the clientelistic political practices and rationale that for long have been embedded in the country's institutions. In accordance, practices of civic engagement and forms of civil organisation that represent a horizontal aggregation of interests are less developed, whereas the local state has traditionally been a quite weak and subordinate welfare provider due to lack of resources, powers, and competence (Arvanitidis, 2017; Maloutas,
1988; Maloutas \& Economou, 1992). An interesting and rather distinct pole here are the religious institutions which are reported to provide social assistance and support in many Mediterranean countries (Mingione \& Oberti, 2003).

As Kandylis and Maloutas (2020, p. 131) eloquently articulate, the provision of affordable housing for immigrants has been "a combination of a market-led laissez-faire approach" where the existing housing stock has absorbed massive migratory movements in "subordinate positions in socioeconomic hierarchy," and an "authoritarian approach assorted with humanitarianism," which "uses displacement as a means of constituting, isolating and disciplining minorities." The market-led laissez-faire approach to affordable housing in the Greek context is related to the absence of state policies for social housing provision, especially during the first two decades after WWII. Through indirect intervention, state policies promoted homeownership, usually via selfpromotion and often via self-construction, allowing family intervention in housing provision while other forms of affordable housing supply were largely absent. The lack of comprehensive affordable housing policy, on the part of the state and the policy choices of no intervention, as far as the market regulates itself, made social housing seem unnecessary. Under these conditions, after the massive arrivals of foreign immigrants in Greece, in the early 1990s, the rented market was more or less the only solution for affordable housing (Arvanitidis, Petrakos, \& Skouras, 2013). The recent severe economic crises lead to massive unemployment, loss of income, and impoverishment along with increased taxation on property, while the state stood unable to address the needs of most vulnerable population groups in need of care and support (Kandylis \& Maloutas, 2020; Maloutas et al., 2020). When refugees arrived, a new accommodation scheme emerged, a "dual housing model" (Kandylis \& Maloutas, 2020), which is based on two distinct accommodation schemes: (a) rented or free temporary housing in apartments (Emergency Support to Integration \& Accommodation Program [ESTIA]) and (b) refugee camps.

On the one hand, the housing model of rented apartments and hotels (the so-called ESTIA) has emerged in different cities. This housing model developed as a partnership between the EU (which provides funding) and the UNHCR (which is responsible for its governance) in collaboration with local authorities and NGOs (which implemented the project in situ). Lease contracts were signed between local landlords and the local actors (the municipality or the NGO), and the criteria set for qualifying such places were typical and minimum standards of housing quality (Arapoglou, Maloutas, \& Siatista, 2019).

On the other hand, the vast majority of newcomers are accommodated in refugee camps, either in crowded 'hot spots' at major ports of entry (considered as irregular migrants) or in refugee camps on the mainland. These "waiting zones" (zones d'attente) are the spatial 
expression of a new and striking phenomenon of "shifting border," where ordinary social and constitutional rights within a liberal democracy are suspended or limited, especially for undocumented migrants or for those who do not have the proper legal status, only after they "pass through our gates" (Shachar, 2020, p. 4). The change in the national perception of immigration, from an innocuous humanitarian and ethic movement into a situation of a civil and national threat, resulted in these "emergency processes" to increasingly exhibit a marginalized and dehumanising attitude towards the newcomers (Bouman, 2016, pp. 85-86).

Apart from the above-mentioned general changes in the housing model of immigrants, we should also add the consequences of the recent economic crisis (2008) on housing inequalities and the aggravation of social-economic conditions of the vulnerable population. A series of bottom-up solidarity practices appear, which managed to support the vulnerable, claiming back the 'citizens' right to the city' (Arampatzi, 2017; Arvanitidis \& Papagiannitsis, 2020; Featherstone, 2015). Thus, informal citizen networks emerged, through mechanisms of citizen engagement and participation in civil actions of various kinds (inter alia: solidarity kitchens, no-middlemen food distribution networks, social health centres, clinics and pharmacies, social education centres), forming a kind of a social safety net able to address the increasing demands for social protection and welfare provision. Interestingly, similar kinds of initiatives appear in response to the massive refugee inflows that the country has recently experienced.

\section{Methodology}

In methodological terms, the article draws upon the experiences of three small and medium-sized Greek cities (Katerini, Larisa, and Volos) to identify the different institutional and policy responses to refugee accommodation, giving rise to different paths and forms of social mobilisation, solidarity, and urban transformation. Since data concerning the location of individual refugee households are not available, the study employs school enrolment data, assuming, along with other studies (Arvanitidis et al., 2020; Vergou, 2019), that there is a strong correlation between school segregation and socio-residential segregation. Such an assumption is validated by the fact that the system of school catchment areas in Greece obligatorily allocates children to schools that are near their residence. Therefore, school enrolments are controlled by the local state and mirror the local population characteristics and environment (its ethnic and socio-economic composition). In this context, we must specify that there is a limitation in this study: the maps rely on school enrolment data and thus on refugees having children at school age only and therefore cannot consider the majority of refugees including young men or couples without children. However, we must specify that accommodation in rented dwellings is provided for the housing needs of vulnerable asylum seekers and refugees (families with an average of five people, single parents, people with serious medical conditions, and people with disabilities; Kandylis, 2019) and thus the majority of beneficiaries are mainly families or single parents and fewer single men.

Furthermore, semi-structured in-depth interviews with 15 local actors (key officials in accommodation and education provision, local government officials, representatives of NGOs, and activists) and 13 refugees were contacted to shed light on the different forms of civil society engagement, refugees' experiences, and policies undertaken. The interviews were conducted between October 2018 and July 2019. Content analysis and corresponding coding were used for analysing the interviews with key categories that emerged through the fieldwork (Bryman, 2004). Cartographic material and mapping techniques are used to display the patterns of residential distribution of refugees housed through the ESTIA program vis-à-vis local populations. Statistical data were also used from the application of Panorama of Greek Census Data (1991-2011) to obtain information on the social-economic profile of the cities at the census tract level (EKKE-ELSTAT, 2015).

\section{The Case Studies}

As mentioned, the current article draws on the experiences of three different, yet typical, Greek urban settings all located close to each other in central Greece. The first, Larisa, concerns a medium-size city where local authorities have an active, hands-on role in refugee settlement, whereas the second, Volos, a somewhat smaller city, has no active role in refugees' accommodation, although there is a refugee camp and shelters for unaccompanied minors at the outskirts of the city. Katerini, the third case study, is a small city, where a local NGO, established by a religious institution, coordinates and manages the housing and integration program for refugees. The specific (socio-cultural, political) contexts of the three case-study cities constitute the underlying environment that informs subsequent policies, the process of integration/segregation, and the barriers and challenges that refugees and the local societies face.

\subsection{Larisa: A Centralist Governance Arrangement}

Larisa is the largest city of the Thessaly Region with 146,926 inhabitants (4.8\% immigrants; EKKE-ELSTAT, 2015). Close to the city $(18 \mathrm{~km})$, in Koutsochero (see Figure 1), there is a refugee camp with 1584 refugees. In 2018, under the supervision of the Municipality of Larisa, refugees were settled in apartments through the provisions of the ESTIA programme. The public benefit enterprise of the Municipality is the coordinator of the housing and integration programs for 430 refugees, both programs funded by the EU. The Municipality has a hands-on role in the spatial allocation and distribution 
of refugees to different neighbourhoods within the city paying due attention to the local housing market conditions (house supply, prices, etc.) and the availability of relevant funding. It is also the agency that deals with the local landlords, specifying appropriate accommodations, signing the contracts, and enforcing the agreements. The criteria set for qualifying such places were typical and minimum standards of housing quality. The choice of the specific beneficiaries of the ESTIA accommodation scheme was made in cooperation with the UNHCR.

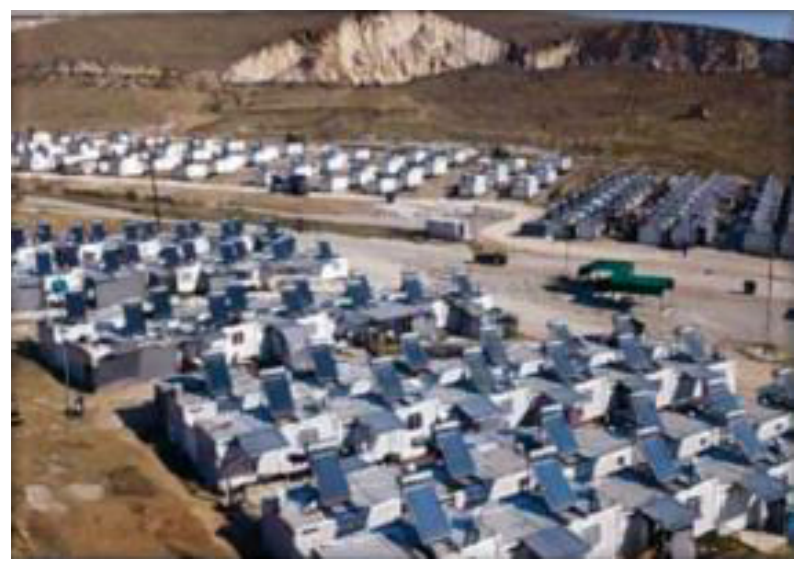

Figure 1. Koutsochero camp in Larisa, September 2020. Source: International Organization of Migration (2020).

The local integration policy is much more oriented towards housing and work for the refugees, through the municipality's services without involvement from other local, actors, such as NGOs. According to this pattern of governance, local arrangements exhibit a clear hierarchy between the different levels of government to ensure that policy implementation at the local level follows central rules and policies (Scholten \& Penninx, 2016). This should be the manner for "an organized society where their marginalized parts, continue their lives and progress....with certainty and order," as the Municipality representative stated (Interview, September 4, 2019).

In the city of Larisa, local solidarity actions took place, especially towards refugees located in Koutsohero camp but also for those in the city. Such actions provided mainly humanitarian aid (food and emergency supplies) in cooperation with other institutional actors and municipal actors and services. The municipal social services (social grocery, shelter for homeless, educational and training activities, etc.) have been the leading actors in this process, with the civil society playing a second, subordinate but supportive role. In that sense, it becomes clear that social initiatives are rather subsidiary whereas the social agenda and policy formulation are set by the local state.

Concerning the ethnic diversity in the city, local authorities seem to have a specific orientation to prevent segregation tendencies. The fear of formations of minority enclaves ('ghetto') within the city seems to be a great concern for the municipality, which intro- duced area-based policies to manage ethnic-cultural differences in a city (e.g., Roma population):

Unfortunately, refugees and Greeks are two worlds that have parallel lives. (Municipality representative, Interview, September 4, 2019)

The example of France, with the uprising of marginalized minorities in the suburbs of Paris is something that we are thinking of. It's a fear for the future. (Municipality representative, Interview, September 4, 2019)

In contrast to the view expressed by the municipality representative were those of the refugees. Interviews revealed the majority of refugees are rather reluctant to live close to either co-ethnics or other refugee groups since they perceive this as a barrier to integration and interaction with the local population. In parallel, concerns were raised by those living close to their co-ethics:

In the specific block of houses, we live together 4-5 families from Syria. It is not so good because we are isolated and it is difficult to learn the Greek language. Also, neighbours keep us at a distance. (Syrian refugee, male, 26 years old, unemployed, Interview, July 25,2019 )

Furthermore, it became apparent that a lack of local language skills is seen by many as the main barrier in the prospect of getting a job in the labour market and a private house when the ESTIA project ends. Interestingly, although many refugees highlighted the favourable qualities of Larissa as a place for permanent residence, they acknowledged the difficulties of getting proper employment that would allow this to happen. One stated:

There are no jobs even for the Greeks, how can we [refugees] find a job? (Syrian refugee, man, 27 years old, unemployed, Interview, July 25, 2019)

Coming back to the issue of segregation, despite local authorities' efforts, segregation tendencies might be in place since the apartments that are made available to refugees in the market are located in specific areas out of the neighbourhoods where high socio-economic categories of natives reside (see Figure 2). This reveals that various factors may affect the development of social and spatial diversities in the city, such as the readiness of the host society to accept refugees in specific locations or the workings of the local property market that define housing availabilities, prices, etc., in addition to the specific housing strategies for the spatial distribution of refugees set by the local authorities. Summing up, in the city of Larisa, institutional changes are less pronounced and based on smaller changes and conversion, with the use of older institutional arrangements. Local state authorities opted for a strategy of organisational changes through the use of existing social assistance 


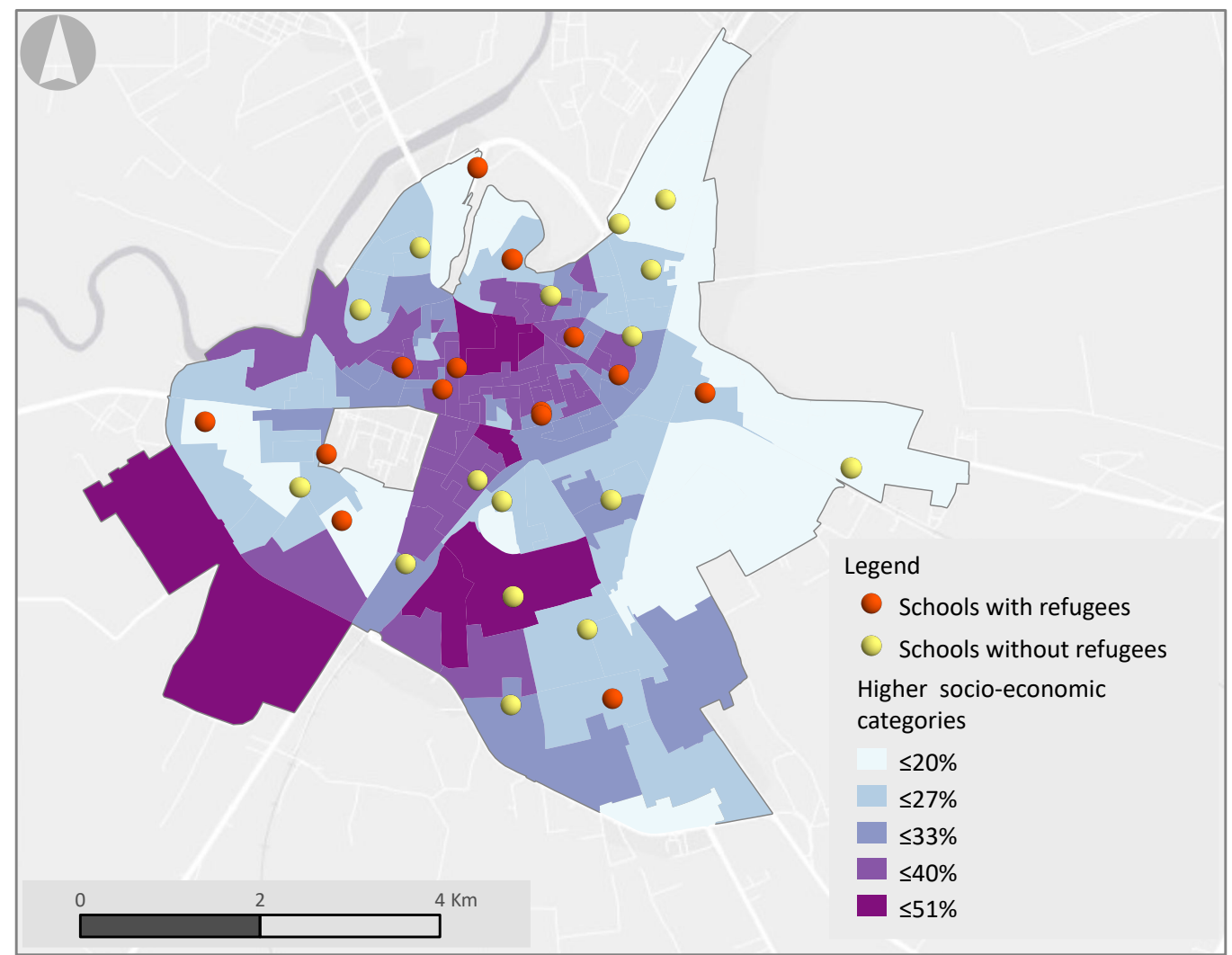

Figure 2. Distribution of higher socio-economic categories (2011) and refugee school population in Larisa. Source: Authors' elaboration and EKKE-ELSTAT (2015).

structures (a municipal public benefit enterprise) and build on previous experiences on local welfare, including refugee reception in the city.

\subsection{Volos: A Decoupled Model of Governance}

According to the 2011 census, the total population of the municipality of Volos is 144,449 inhabitants. The percentage of non-Greeks living in the city is $6.8 \%$ (EKKE-ELSTAT, 2015). There is a refugee camp located on the outskirts of the city, near a waste disposal site and close to the industrial area of the city (see Figure 3). Also, there is a hotel

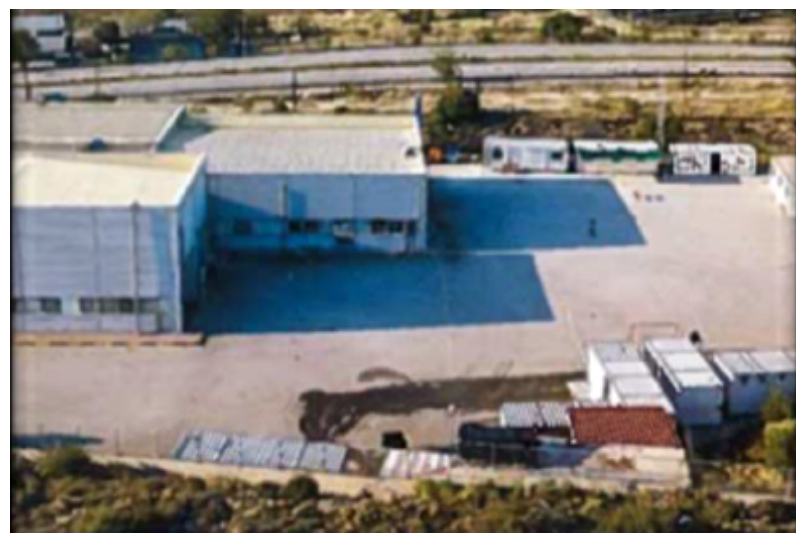

Figure 3. Moza camp in Volos, September 2020. Source: International Organization of Migration (2020). and two shelters for unaccompanied minors outside the city, which are operated by a national NGO (ARSIS). The local authorities and municipal actors shaped and enforced this model of local-state policy. At the beginning of the dispersal policy set by the Greek state, the Municipality of Volos asked the Ministry of Defence to place refugees "outside the city" (E-Thessalia, 2016). Refugee children, in the beginning, had non-formal education but attended language courses given by trained personnel inside the camp. After the refusal of the nearby village to accept them in their school, enrolment took place in an area near a Roma settlement in the working-class area of Nea Ionia, Volos (Vergou, 2019).

However, local solidarity groups have been quite active in the city, providing informal support to the newcomers' settlement process, especially in the areas of education and basic needs. Although some solidarity actions took place in 2016 when refugees settled in the camp (Moza) on the outskirts of the city, such voices and activities were consolidated after the objections of several Greek parents to accept enrolment of refugee children in the school their children attended, which was near a refugee shelter in the north part of the city (E-Thessalia, 2018). The outburst of such xenophobic instances triggered new forms of small but robust solidarity mobilisations of active citizens in the city, finally succeeding in overcoming resistance and allowing refugee enrolment in that school. The absence of any support from the local state authorities along with the outburst of racism 
and xenophobic behaviour from the Greek parents were the key drivers of the aforementioned solidarity actions. These local initiatives of support to refugees continued under different forms (cultural activities, first aid help, etc.) until the closure of the shelter at the end of 2020 and the transfer of refugees to other camps around Greece. However, other grassroots initiatives have not ceased providing mainly food support and emergency supplies to refugees housed in the Moza camp.

The pattern of the city of Volos seems to match, theoretically, to a decoupling pattern (Scholten, 2013; Scholten \& Penninx, 2016), which is characterized by the absence of any mechanisms of cooperation and political interaction between government levels and represents a new wave of local policies of exclusion. During the relocation of refugees to the mainland, this pattern of absence of coordination took more severe conflicts and competitive forms between different levels of government due to political and institutional factors (see Spencer, 2018). In this case, municipalities or regional authorities challenged the central state and not only did something different (as it happens in decoupling patterns) but refused to comply with the central decisions of the state. To that end, the local authorities either refused to join the ESTIA program or protested against the accommodation of refugees. As a result, in some cases, the opening of reception facilities in buildings, hotels, and open centres were cancelled altogether.
In Volos, as seen in Figure 4, refugees are accommodated in facilities at the margins of the city, outside the urban fabric. Moreover, schools with reception classes for refugees are located in the North-West suburbs, where there is a high concentration of lower socio-economic categories and of Roma people in contrast to the northeast neighbouring areas which house higher socio-economic categories. Consequently, municipal intervention reinforced segregation processes in the city and eventually refugees were excluded from the centre of the city. In summary, the pattern of the city matches a decoupling governance arrangement, where refugees are excluded from the city. In this case, institutional changes are taking the form of subsidiary arrangements, where other actors are taking action, such as a national NGO (Arsis), undertaking an important complementary role in housing unaccompanied minors.

\subsection{Katerini: A Localist, bottom-up Governance Arrangement}

Katerini is a medium-size city (in Greek terms) of 85,851 inhabitants. The percentage of non-Greeks living in the city is $5.8 \%$ (EKKE-ELSTAT, 2015). Close to the city (about 13 kilometres), in Kato Milia village, there is a refugee camp which accommodates approximately 350 refugees (see Figure 5). After the closure of the national borders in March 2016 when thousands of refugees and

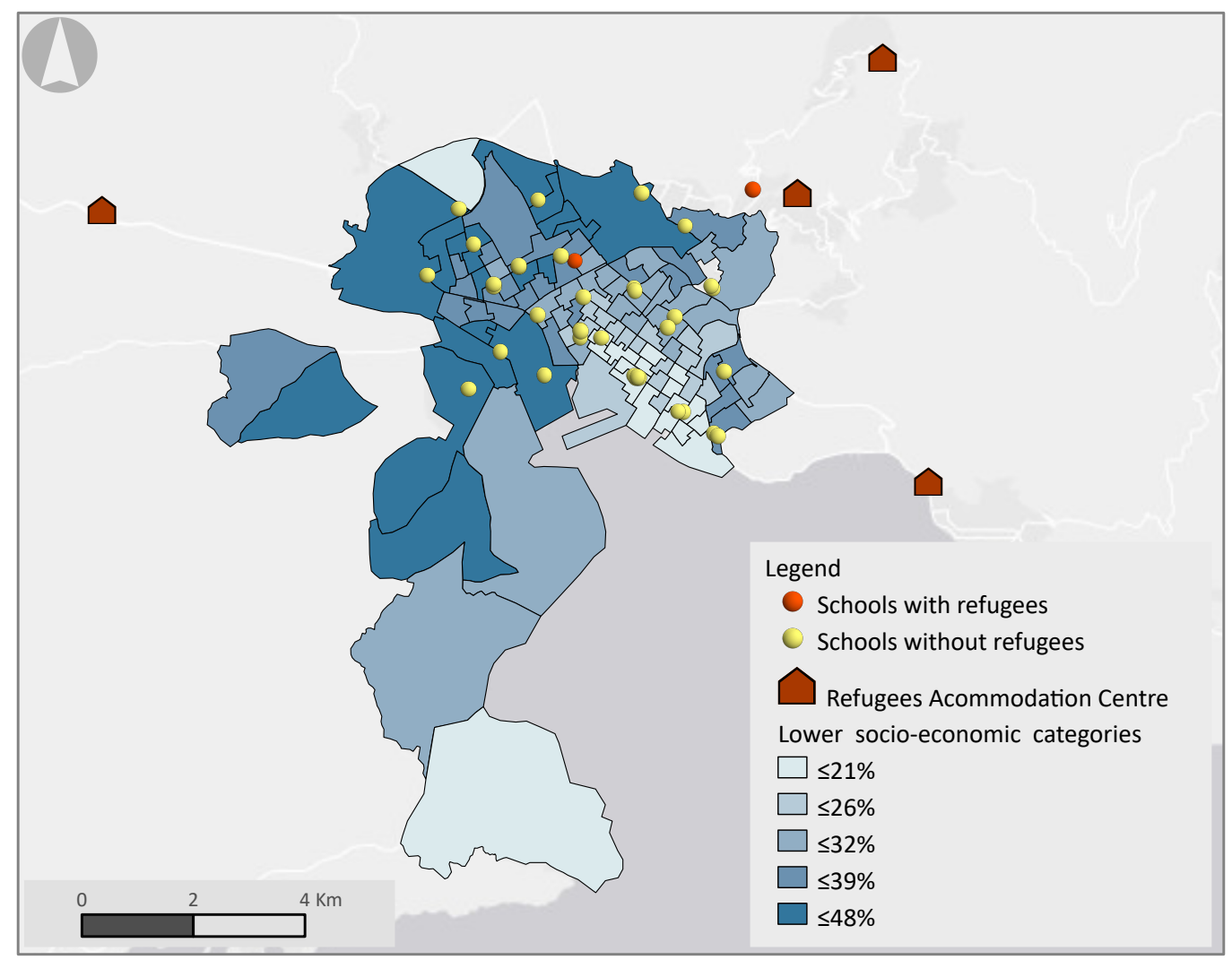

Figure 4. Distribution of lower socio-economic categories (2011) and refugee school population in Volos. Source: Authors' elaboration and EKKE-ELSTAT (2015). 
asylum seekers were left stranded at Idomeni camp in northern Greece, local volunteers from Katerini, who were members of the charitable activity of the Social Grocery of the Evangelical Church, began to provide support to refugees and ended up transferring those most vulnerable into their own apartments in Katerini. Then, they established the NGO Perichoresis to support refugees in need. The NGO operates under the auspices of the Greek Evangelical Church of Katerini and it manages around 130 apartments, accommodating more than 598 refugees. Financial support comes from both the ESTIA housing program and other humanitarian organisations and church networks, mainly from Germany, such as Brot für die Welt (Bread for the World), Hilfe für Brüder International (Help for Brothers International) a mission association of the German Evangelical Alliance and a broader international church network of ACT Alliance and Diakonie Katastrophenhilfe (Diakonie Emergency Aid). A global, cross-border philanthropic foundations network seems to filter into the governance of residential accommodation of refugees and local welfare solutions in the city. Another element that indicates the relative success of the local-based NGO approach is its ability to compete and gain institutional resources, in most cases through competitive processes and espousing a 'contract culture,' either for housing projects (ESTIA) or integration programs (HELIOS).

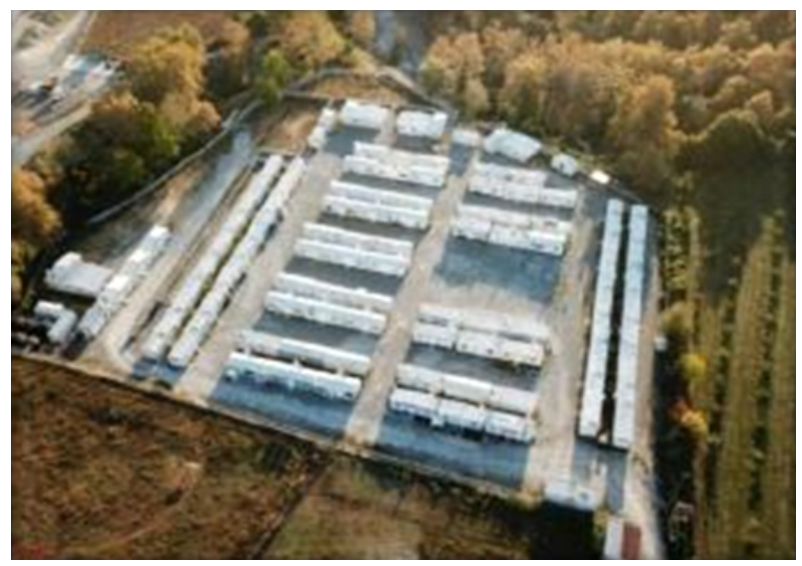

Figure 5. Kato Milia camp in Katerini, September 2020. Source: International Organization of Migration (2020).

In our study, we understand that the local NGO Perichoresis in Katerini played a crucial role in overcoming tensions between locals and newcomers in the 'spatial arena' and supported the smooth integration of refugees within the local community. Not only did it undertake the responsibility of running the ESTIA housing program, but it also established several other projects and activities to promote refugee integration and access to employment such as an intercultural cooking club, a sewing club and workshops, group therapy sessions for women and children, sports activities, English and Greek language lessons, and more recently, a social cooperative enterprise (Peri-Ergon) where natives and refugees make products from recyclable materials from refugee boats crossing the Aegean. Moreover, some refugees work as translators and mediators in accommodation facilities for refugees either in the city of Katerini or in the neighbouring city of Grevena. However, it was also found, but to a less degree than our case study in Larisa, that refugees are located out of the areas where higher socio-economic categories of natives reside (see Figure 6). This indicates that various factors played a role in social-spatial diversity in the city and key elements for the different paths of spatial allocation and distribution of refugees to different neighbourhoods within cities.

As our interviews made apparent, the success of the local NGO's social assistance depends on its ability to gain the support of local civil organisations and society in general. They were concerned about the public opinion and the views of the community especially in terms of refugees getting a kind of special treatment over the poor and vulnerable local people. For that reason, Perichoresis has established a new project where vulnerable native families can also benefit from subsidized housing:

The integration of vulnerable Greek families within the same project of housing for refugees was very important for the local society. (Perichoresis representative, Interview, September 9, 2019)

We need to show to the local society that refugees can contribute to the community...[that they] are equal to the other members of the society. [They should] find their own space in the local society...stand on their own two feet again. (Perichoresis representative, Interview, September 9, 2019)

The Perichoresis representatives believe that housing provision would help to reduce or eliminate racism, harassment, and other forms of discrimination. They stated that locals were not familiar with the cultural practises of the incomers, especially their social gathering in central public spaces, something that aggravates fear, especially at the beginning of their settlement:

The local community can see now that refugees have a house and are integrated. So they don't feel fear. They wear headscarves [refugees] but when they have a house and a job they are not gathering at the park. When they have a house and a job they don't feel excluded or create problems. In contrast, in big cities like Thessaloniki, there are many violent incidents with refugees. (Perichoresis representative, interview, September 9, 2019)

In closing the Katerini case, a final point should be made. In the Greek welfare state, church and religious institutions have a major role in the field of social assistance. Depending on the local context, religious institutions intervene only in extreme cases of poverty and 


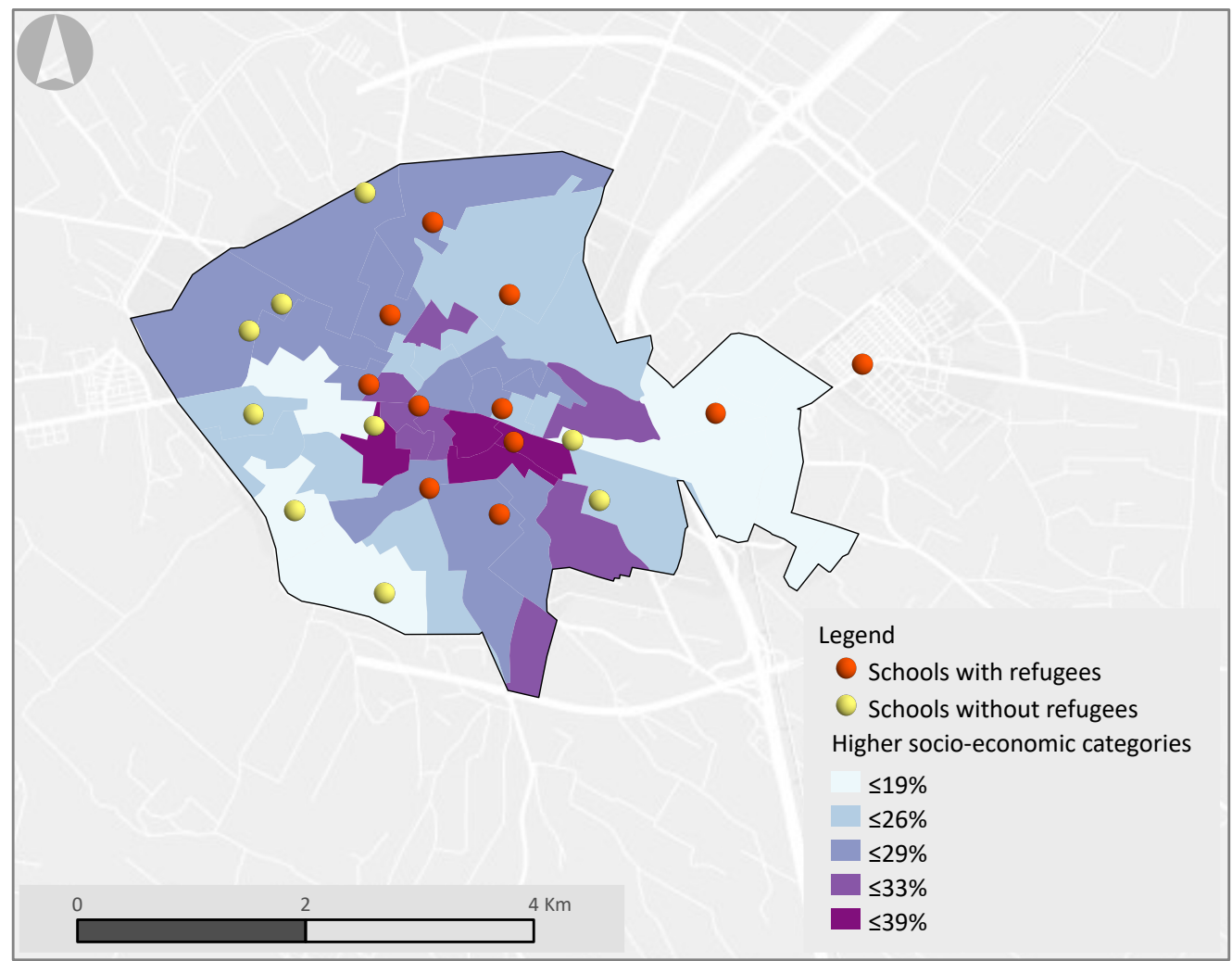

Figure 6. Distribution of higher socio-economic categories (2011) and refugee school population in Katerini. Source: Authors' elaboration and EKKE-ELSTAT (2015).

social exclusion or become a full partner of the local institutional regime (Mingione \& Oberti, 2003, p. 13). In our case, the religious organisation under study maintains a major role in both cases, with a great deal of autonomy and more recently, in accommodation and integration programs of refugees.

There is cooperation with the municipality but they don't want to interfere with the management of the accommodation and processes of refugees' integration. Generally, we work as a link between the municipality and the refugees. (Perichoresis representative, Interview, September 9, 2019)

In summary, there are different forms of institutional processes and changes regarding the accommodation of refugees in Katerini. While the role of a religious organisation as a traditional local welfare provider upraised, there was a shift of the welfare mix from caring tasks to NGOs and civil society interventions, enabling flexibility and swiftness in response by relying on global, cross-border philanthropic foundations network, donors, and directcontract arrangements. However, the subsidiary position of religious organisations (as well as of civil society) in the local welfare has a diversified role and must undertake some risks. An important risk is the possibility of public institutions' passivity, where social responsibilities delegated from the local state to civil society (Kazepov, 2010; Oosterlynck et al., 2013a). Local institutional passivity coincides with the strong presence of a local, religious agency which may also inhibit the proper public sector engagement and the formation of reliable, accountable, and credible public responsibility (Allen, Barlow, Leal, Maloutas, \& Padovani, 2004, p. 106).

\section{Conclusions}

The three examples of municipal governance arrangements illustrate the following different local government actions and social initiatives associated with urban areas in small and medium-sized cities in Greece: A centralist approach in accommodation and integration of refugees (Larisa); a decoupled governance arrangement where refugees are excluded from the urban fabric of the city (Volos); and a localist arrangement through a localbased NGO (religious organisation) with a more handson and inclusive approach for the integration of refugees (Katerini). These approaches show that municipal intervention has different variations, but there are many ways to shape or hinder urban inequalities and segregation processes. Different power relations, links and dynamics associated with local political arrangements of refugee housing give rise to distinctive processes of the social division of space.

All three cities relied on emergency measures that allowed them to either create a structure of responsibilities and arrange cooperation or emphasise the limited capacities in refugee accommodation. The city of Larisa 
did not pass their responsibilities of refugee accommodation on to others or only did so to a limited degree. They used the already existing social assistance structures built on previous experiences (a municipal public benefit enterprise), following the example of other neighbouring municipalities and thus chose a strategy of organisational change. Therefore, the municipality was better prepared and able to implement smaller changes and adopt a social welfare approach to immigration, including refugee reception and accommodation in the city. In contrast, the municipality of Volos chose a more decoupled governance arrangement (Scholten, 2013; Scholten \& Penninx, 2016) where refugees were excluded from the urban fabric. In structural terms, the city is rather different from Larisa, not only concerning the organisational structure of social welfare provision but also in the way that the municipality deals with migration and diversity. Local officials in Volos framed the settlement of the newcomers as a problem and asked for refugees to be placed outside the city. In contrast, the municipality of Katerini opted for a no-involvement strategy by delegating its responsibilities to third-party actors (e.g., a local-based NGO called Perichoresis, supported by a religious organisation). In this case, we observed the important risk of public institutions' passivity, where social responsibilities were delegated from local state to civil society (Kazepov, 2010; Oosterlynck et al., 2013b). However, in all three cases, regardless of the different approaches, there is a tendency to allocate refugee housing or other accommodation relatively closer to neighbourhoods with a lower socio-economic profile than to those with affluent residents. These common strategies of local governments to allocate undesirable populations in specific areas are similar to other forms of exclusion of certain minority groups in urban areas, such as the Roma population (Vergou, 2017).

Within this context, we observed different forms of institutional processes and changing aspects that may lead to broader institutional changes. Firstly, the role of a local public institution and its multi-level governance approach: The recent reforms in migration policy regarding refugee reception and accommodation in different cities in Greece and the decentralisation of accommodation policies have provided municipalities with new regulatory powers. These brought about the need for coordination of the increased number of various actors with different interests, values, and organisational frameworks (such as international organisations, NGOs, local solidarity initiatives, and religious organisations). In this sense, these new forms of governance may well be differentiated by their local political strategies, the involvement of civil society organisations, and the cooperation with different actors.

Another aspect of institutional change can be observed through the transition from public intervention to the involvement of civil society. Although local policies are very much dependent on national regulations, there is a degree of autonomy concerning integration policies
(Scholten \& Penninx, 2016). Furthermore, it seems that sub-national levels of governance (local states, regions) are more resilient and able to develop institutional innovation as "laboratories" concerning social policies, citizenship, social inclusion, and participation (Kazepov, 2008). However, the involvement of civil society organisations and mixed networks plays a diverse role which entails some risks, especially when local authorities resort to a passive role in the provision of local welfare policies, as we have seen in the Katerini case. As the welfare state eroded, the role of the Church as the traditional local welfare provider was elevated-this was also reported in other countries (Oberti \& Preteceille, 2018). This shifted the welfare mix of social care tasks to NGOs initiatives and enabled flexibility and swiftness in response by relying on private finance, donors, and direct-contract arrangements. The intermediary structures involved in the local systems, which are diverse and range from large religious organisations to small volunteer groups, may fill in the void left by the absence of public interventions (Katerini case). Their success in combatting social exclusion issues certainly depends on the local contexts but we also have to keep in mind that in some cases such intervention might be seen as controversial or contested "battlegrounds" either between state and local state actors (Campomori \& Ambrosini, 2020, p. 3) or among public and non-public actors. Furthermore, bureaucratic rigidity, lack of control, and strong clientelistic networks seem to hinder innovative developments.

Finally, another aspect of change can be observed through the effectiveness of civil society's social initiatives and civil actions of various kinds. Flexible forms of interaction between public actors and bottom-up initiatives seem to be effective in tackling housing and other pressing social issues of refugee integration, as we have seen in all three cases. When the community social initiatives are aided by adequate resources and supportive institutions, they can be intermediaries between the needs of refugees and the local state welfare services, and this deserves more research attention. Local institutions are better equipped to understand different levels of interactions and complex social relations at socioterritorial levels. In this context, the local spatial level as a relational setting enhances the sentiment of security and belonging and creates a sense of community which is necessary for refugees to seek a new life (Blokland, 2017), but proximity alone is not sufficient to create strong ties and support. Bringing diverse social groups together in mixed neighbourhoods does not automatically result in networking and community support but in contrast, research shows that households used varied strategies to maintain their distinct class position and control proximity and distance to other social groups (Maloutas, 2020; Weck \& Hanhörster, 2015).

Concluding, we found that a kind of cooperation between state authorities and community organisations is rather beneficial. Allocating different tasks and responsibilities within local welfare governance would lead to 
the advancement of refugees' integration. Taking into consideration the absence of affordable housing in the Greek welfare context (Kandylis \& Maloutas, 2020), public actors, and state institutions can upscale successful practices of refugee accommodation in cities through municipal housing provision (Arapoglou et al., 2019), using their experience of cooperating with accountable and credible community organisations and providing adequate state resources for the development of affordable housing. By framing the case of refugee accommodation as opening up new opportunities, we can observe that housing policies, through the use of municipal services and experiences of the ESTIA program, may result in more inclusive housing for refugees. While the role of the state may be changing and processes of state-led privatisation have emerged, what remains ever more important today is a more comprehensive welfare policy approach. In this approach, affordable housing is emerging as a fundamental social right, while at the same time, housing markets seem to be failing to address persistent social needs.

\section{Acknowledgments}

We would like to thank the anonymous reviewers and the editors for their constructive comments and suggestions on the earlier version of this article. Some of the ideas and arguments developed in this article were partly inspired by and based on research conducted in the project INSERT (2018-2020) funded by the Hellenic Observatory Research Calls Programme-London School of Economics and Political Science (LSE) under grant agreement (09/18/2018).

\section{Conflict of Interests}

The authors declare no conflict of interests.

\section{References}

Allen, J., Barlow, J., Leal, J., Maloutas, T., \& Padovani, L. (2004). Housing and welfare in Europe. Oxford: Blackwell.

Andreotti, A., Mingione, E., \& Polizzi, E. (2012). Local welfare systems: A challenge for social cohesion. Urban Studies, 49(9), 1925-1940.

Arampatzi, A. (2017). The spatiality of counterAusterity politics in Athens, Greece: Emergent 'urban solidarity spaces.' Urban Studies, 54(9), 2155-2171.

Arapoglou, V., Maloutas, T., \& Siatista, D. (2019). Vacant houses: A resource for social housing schemes and

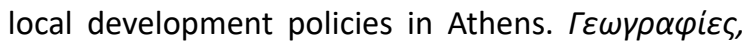
33, 52-64.

Arbaci, S. (2019). Paradoxes of segregation: Housing systems, welfare regimes and ethnic residential change in Southern European Cities. Oxford: Wiley-Blackwell. Arvanitidis, P. (2017). The concept and determinants of civic engagement. Human Affairs, 27(3), 252.

Arvanitidis, P., \& Papagiannitsis, G. (2020). Urban open spaces as a commons: The credibility thesis and common property in a self-governed park of Athens, Greece. Cities, 97, 102480.

Arvanitidis, P., Petrakos, G., \& Skouras, D. (2013). Immigrant location patterns in a Southern European metropolis: The case of Athens. In J. Klaesson, B. Johansson, \& C. Karlsson (Eds.), Metropolitan regions: Knowledge infrastructures of the global economy (pp. 473-514). Berlin and Heidelberg: Springer.

Arvanitidis, P., Vergou, P., Manetos, P., \& Grigoriou, G. (2020). Immigrant and refugee segregation dynamics (InSert). London: LSE. Retrieved from https://www.Ise.ac.uk/Hellenic-Observatory/ Research/Projects-2018/Immigrant-and-RefugeeSegregation-Dynamics

Blokland, T. (2017). Community as urban praxis. Cambridge: Polity Press.

Bouman, S. (2016). Strangers at our door. Cambridge: Polity Press.

Bryman, A. (2004). Social research methods. New York, NY: Oxford University Press.

Bureau of European Policy Advisers. (2011). Empowering people, driving change: Social innovation in the European Union. Brussels: European Commission. Retrieved from http://ec.europa.eu/bepa/pdf/ publications_pdf/social_innovation.pdf

Campomori, F., \& Ambrosini, M. (2020). Multilevel governance in trouble: The implementation of asylum seekers' reception in Italy as a battleground. Comparative Migration Studies, 8(1), 1-19. https://doi.org/ 10.1186/s40878-020-00178-1

EKKE-ELSTAT. (2015). Panorama of Greek census data 1991-2011. Panorama. Retrieved from https:// panorama.statistics.gr

E-Thessalia. (2016, March 17). The municipality of Volos requests financial support in order to accommodate refugees. E-Thessalia. Retrieved from https://e-thessalia.gr/o-dimos-volou-zitai-lefta-giana-filoxenisi-prosfyges-ke-apaxioni-ton-olv

E-Thessalia. (2018, October 19). The parents from lolkos High school speak for the refugees. E-Thessalia. Retrieved from https://e-thessalia.gr/goneis-toygymnasioy-iolkoy-gia-ta-prosfygopoyla-denechoyme-akraies-antilipseis-oi-provlimatismoimas-einai-vasimoi

European Council. (2016, March 18). EU-Turkey statement [Press release]. Retrieved from https://www. consilium.europa.eu/en/press/press-releases/2016/ 03/18/eu-turkey-statement/\#

Featherstone, D. (2015). Thinking the crisis politically: Lineages of resistance to neo-liberalism and the politics of the present conjuncture. Space and Polity, 19(1), 12-30.

Greek Government. (2020a). Ministry Act 21210: Implementation of ESTIA II program: Housing program for applicants of international protection 
(Government Gazette 3077B/24.07.2020). Athens: Greek Government. Retrieved from https://www. e-nomothesia.gr/kat allodapoi/prosphuges-politikoasulo/koine-upourgike-apophase-21210-2020.html

Greek Government. (2020b). Law 4674: Strategies for the development of the local state organizations (Government Gazette 53A/11.03.2020). Athens: Greek Government. Retrieved from https://www. enomothesia.gr/autodioikese-demoi/nomos-46742020-phek-53a-11-3-2020.html

Hellenic Integration Support for Beneficiaries of International Protection. (2019). Supporting the Cities Network for Integration [Press release]. Retrieved from https://greece.iom.int/en/supporting-\%E2\%80 \%98cities-network-integration\%E2\%80\%99

International Organization of Migration. (2020). Factsheet, September 2020. Geneva: International Organization of Migration. Retrieved from https://greece. iom.int/sites/greece/files/__Merged\%20Factsheet \%20Sep_20_0.pdf

Kandylis, G. (2019). Accommodation as displacement: Notes from refugee camps in Greece in 2016. Journal of Refugee Studies, 32(1), i12-i21. https://doi.org/ 10.1093/jrs/fey065

Kandylis, G., \& Maloutas, T. (2020). From laissez-faire to the camp: Immigration and the changing models of affordable housing provision in Athens. In E. Bargelli \& T. Heitkamp (Eds.), New developments in Southern European housing (pp. 127-150). Pisa: Pisa University press.

Kazepov, Y. (2008). The subsidiarization of social policies: Actors, processes and impacts. European Societies, 10(2), 247-273. https://doi.org/10.1080/ 14616690701835337

Kazepov, Y. (2010). Rescaling social policies: Towards multilevel governance in Europe. Surrey: Ashgate.

Maloutas, T. (1988). Introduction. Welfare state: The prototype and the Greek version. In T. Maloutas \& D. Economou (Eds.), Problems of the development of the welfare state in Greece. Athens: Exandas Editions.

Maloutas, T. (2020). Vertical social differentiation as segregation in spatial proximity. In S. Musterd (Ed.), Handbook of urban segregation (pp. 325-345). Cheltenham and Northampton, MA: Edward Elgar.

Maloutas, T., \& Economou, D. (Eds). (1992). Social structure and urban organization: The geography of collective consumption in Athens. Thessaloniki: Paratiritis.

Maloutas, T., Siatista, D., \& Balambanidis, D. (2020). Access to housing and social inclusion in a postcrisis era: Contextualizing recent trends in the city of Athens. Social Inclusion, 8(3), 5-15.

Mingione, E., \& Oberti, M. (2003). The strangle against social exclusion and the local level: Diversity and convergence in European Cities. European Journal of Spatial Development, 1, 1-23. Retrieved from https://archive.nordregio.se/Global/Publications/ Publications\%202017/Refereed_1_ Mingione(2003).pdf
Oberti, M., \& Preteceille, E. (2018). Urban segregation, inequalities and the local welfare: The challenges of neoliberalism. In A. Andriotti, D. Benasi, \& Y. Kazepov (Eds.), Western capitalism in transition: Global processes, local challenges. Manchester: Manchester University Press.

Oosterlynck, S., Kazepov, Y., Novy, A., Cools, P., Barberis, E., Wukovitsch, F., . . Leubolt, B. (2013a). The butterfly and the elephant: Local social innovation, the welfare state and new poverty dynamics (ImPRovE Discussion Paper No. 13(03)). Antwerp: Herman Deleeck Centre for Social Policy, University of Antwerp.

Oosterlynck, A., Kazepov, Y., Novy, A., Cools, P., Wukovitch, F., Saruis, T., . . . Leubolt, B. (2013b). Exploring the multi-level governance of welfare provision and social innovation: Welfare mix, welfare models and rescaling (ImPRovE Discussion Paper No. 13/12). Antwerp: Herman Deleeck Centre for Social Policy, University of Antwerp.

Penninx, R., \& Garcés-Mascareñas, B. (2016). The concept of integration as an analytical tool and as a political concept. In B. Garcés-Mascareñas \& R. Penninx (Eds.), Integration processes and policies in Europe. Context, levels and actors (IMISCOE research series; pp. 11-30). London: Springer Open.

Scholten, P. W. A. (2013). Agenda dynamics and the multi-level governance of intractable policy controversies: The case of migrant integration policies in the Netherlands. Policy Sciences, 46(3), 217-236. https://doi.org/10.1007/s11077-012-9170-x

Scholten, P., \& Penninx, R. (2016). The multilevel governance of migration and integration. In B. GarcésMascareñas and R. Penninx (Eds.), Integration processes and policies in Europe (IMISCOE research series; pp. 91-108). https://doi.org/10.1007/978-3319-21674-4_6

Shachar, A. (2020). The shifting border: Legal cartographies of migration and mobility. Manchester: Manchester University Press.

Spencer, S. (2018). Multi-level governance of an intractable policy problem: Migrants with irregular status in Europe. Journal of Ethnic and Migration Studies, 44(12), 2034-2052. https://doi.org/ 10.1080/1369183X.2017.1341708

United Nations High Commissioner for Refugees. (2019). Greece accommodation. Factsheet, March 2019. Geneva: United Nations High Commissioner for Refugees. Retrieved from http://estia.unhcr.gr/en/ greece-accommodation-update-february-2019

Vergou, P. (2017). Residential segregation, education and the city: Educational strategies of middle class groups in West Attica. In T. Maloutas and S. Spyrellis (Eds.), Athens social atlas: Digital compendium of texts and visual material. Retrieved from https://www.athenssocialatlas.gr/en/article/ segregation-education-and-the-city

Vergou, P. (2019). Living with difference: Refugee education and school segregation processes in Greece. 
Urban Studies, 56(15), 3162-3177.

Weck, S., \& Hanhörster, H. (2015). Seeking urbanity or seeking diversity: Middle-class family households in a mixed neighbourhood in Germany. Journal of Housing and the Built Environment, 30(3), 471-486.

\section{About the Authors}
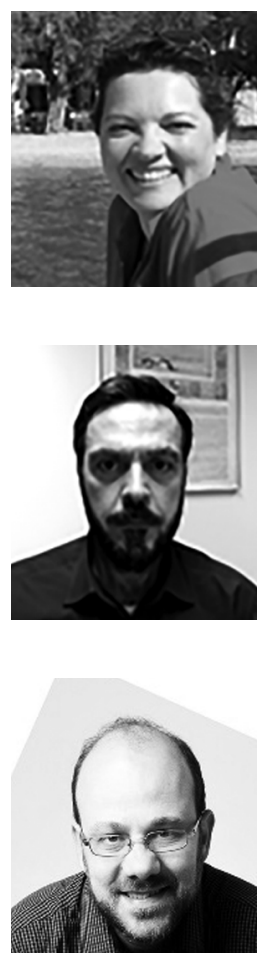

Pinelopi Vergou is a Member of the Laboratory Teaching Personnel at the Department of Economics, University of Thessaly, Greece. Her research focuses on social and ethnic residential segregation, education inequalities, immigrants' integration, local welfare policies, and social initiatives. She holds a PhD in Social Geography, an MSc in Political Science and Sociology, and a Diploma in Political Science and International Studies.

Paschalis A. Arvanitidis (MEng, MLE, PgC, PhD) is Associate Professor of Institutional Economics. His specialisation is on institutional economics, the commons and urban economics and property markets, whereas current research focuses on issues of urban commons and immigrant and refugee spatialities. Paschalis is the author of a research monograph published by Routledge and of other articles published in collective volumes and peer-reviewed journals such as European Politics and Society, Current Issues in Tourism, Cities, and Public Choice.

Panos Manetos is a Member of the Laboratory and Teaching Personnel at the Department of Planning and Regional Development, University of Thessaly. His fields of interest include fuzzy applications, integrated urban models, quantitative spatial analysis, web GIS applications, and spatial databases. He has implemented several national and European GIS projects, the majority of which involved designing integrated and complex geo-databases. 